$42 \%$ of left-handed children with immune disorders had dyslexia $(\mathrm{P}<.01)$; and $32 \%$ of dyslexic children with immune disorders were left-handed $(\mathrm{P}<.05)$. Of the three factors, handedness was the most important association. (Tonnessen FE et al. Dyslexia, left-handedness, and immune disorders. Arch Neurol April 1993; 50: 411-416). (Reprints: Dr Tonnessen, Center for Reading Research, Box 2504, Ullandhaug, N-4004 Stavanger, Norway).

COMMENT. The Geschwind theory postulates a single factor underlying dyslexia, left-handedness, and immune disorders. The results of this study suggest that left-handedness and dyslexia are more important than immune disorders in a possible three-way association of these conditions.

\title{
DYSLEXIA: A VISUAL DISORDER?
}

Visual evoked potentials were measured with scalp electrodes in eight reading-disabled children aged 8 to 11 years and compared to a control group of 13 age-matched normal readers at the School of Optometry, University of Missouri, St Louis. Using a steady background and a low-spatial-frequency target ( 0.5 cycle/degree visual angle), the latencies of the early components (N1 and P1) of the VER were longer and the amplitude of the subsequent (P1N2) component was smaller in the reading-disabled than in normal readers. A flickering background increased the latency and reduced the amplitude of the early components of the VER in normal readers, whereas in reading-disabled children only the amplitude was affected. These differences were most likely due to a sensory deficit and slowed response in the magnicellular visual pathway of reading-disabled children. (Lehmkuhle $S$ et al. A defective visual

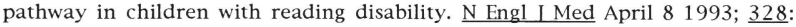
989-996). (Reprints: Stephen Lehmkuhle PhD, School of Optometry, University of Missouri-St Louis, 8001 Natural Bridge Rd, St Louis, MO 63121).

COMMENT. These findings are supported by previous anatomical and electrophysiological studies that have demonstrated a defective magnicellular visual pathway in dyslexic subjects. A cause-and-effect relation between these slowed visual responses and the reading disability remains to be determined.

\section{TOXIC DISORDERS}

\section{COGNITIVE IMPROVEMENT FOLLOWING LEAD CHELATION} The short ( 7 weeks) and long (6 months) term effects of lowered blood" lead levels on cognitive performance were measured in 154 previously untreated lead-poisoned children, aged 13 to 87 months, examined at the Department of Pediatrics, Albert Einstein College of Medicine, Montefiore 
Medical Center, Bronx, NY. Pre-treatment blood lead levels were $25-55 \mathrm{mcg} / \mathrm{dL}$, and erythrocyte protoporphyrin levels were $>0.65 \mathrm{mcmol} / \mathrm{L}$, in children enrolled. Housing inspections and abatement procedures were performed as necessary, and an iron supplement $(6 \mathrm{mg} / \mathrm{kg}$ day) was prescribed for children (39\% of group) with ferritin levels $<16 \mathrm{mcg} / \mathrm{L}$. Those with positive lead mobilization tests ( $40 \%$ of group) were administered a 5 day course of EDTA. Cognitive development was measured by the Bayley and Stanford-Binet 1) before treatment, 2) at 7 weeks, and 3) 6 months after enrollment. The Stanford cognitive index (CI) increased 1 point for every decrease of $3 \mathrm{mcg} / \mathrm{dL}$ in blood lead level after 6 months but not at 7 weeks after treatment. A moderate correlation of test performance with ferritin levels was the only significant change at short term: every increase of $3 \mathrm{mcg} / \mathrm{L}$ in serum ferritin was associated with an increase of 1 point on the CI. (Ruff HA et al. Declining blood lead levels and cognitive changes in moderately lead-poisoned children. IAMA April 7 1993; 269: 1641-1646). (Reprints: Holly A Ruff PhD, Department of Pediatrics, Room 222, Kennedy Center, Albert Einstein College of Medicine, Bronx, NY 10461).

COMMENT. The results suggest an association between decreases in blood lead level and cognitive improvements in lead-poisoned children. The authors remain cautious in making causal correlations, and they admit a possible contribution of iron supplements or other factors in the cognitive improvements observed.

A study of lead-contaminated soil abatement in Boston and blood lead levels of 152 urban children less than 4 years of age showed that soil abatement around homes results in only a modest decline in blood lead levels ( $2.44 \mathrm{mcg} / \mathrm{dL}$ after an 11 month interval). The median surface soil lead levels were 2075 ppm before abatement and 105 ppm after abatement. Urban children with low-level lead exposure are not appreciably benefited by soil abatement programs. (Weitzman $\mathrm{M}$ et al. IAMA April 7 1993; 269: 1647-1654). An estimated 3 million children in the United States and $69 \%$ of children, 6 months to 5 years of age, in Boston have blood lead levels $>10 \mathrm{mcg} / \mathrm{dL}$, sufficient to impair intelligence and development. (Also see Editorial, Binder S, Matte T, IAMA 1993; 269: 1679).

\section{ORGANOPHOSPHATE AND DELAYED POLYNEUROPATHY}

A 3-year-old boy was admitted to the North Shore University Hospital, Manhasset, NY, with acute organophosphate (Dursban) roach poisoning. He was comatose, his pupils were pinpoint, and he had tachycardia, frothy oral secretions, and fasciculations of the eyelids and extremities. Following treatment with atropine and phenytoin, he recovered consciousness and the 